\title{
An analysis of the time course of attention in preview search
}

\author{
GLYN W. HUMPHREYS and BETTINA JUNG STALMANN \\ University of Birmingham, Birmingham, England \\ and \\ CHRIS OLIVERS \\ Vrije Universiteit, Amsterdam, The Netherlands
}

\begin{abstract}
We used a probe dot procedure to examine the time course of attention in preview search (Watson \& Humphreys, 1997). Participants searched for an outline red vertical bar among other new red horizontal bars and old green vertical bars, superimposed on a blue background grid. Following the reaction time response for search, the participants had to decide whether a probe dot had briefly been presented. Previews appeared for 1,000 msec and were immediately followed by search displays. In Experiment 1, we demonstrated a standard preview benefit relative to a conjunction search baseline. In Experiment 2, search was combined with the probe task. Probes were more difficult to detect when they were presented 1,200 msec, relative to $800 \mathrm{msec}$, after the preview, but at both intervals detection of probes at the locations of old distractors was harder than detection on new distractors or at neutral locations. Experiment $3 \mathrm{~A}$ demonstrated that there was no difference in the detection of probes at old, neutral, and new locations when probe detection was the primary task and there was also no difference when all of the shapes appeared simultaneously in conjunction search (Experiment $3 \mathrm{~B}$ ). In a final experiment (Experiment 4), we demonstrated that detection on old items was facilitated (relative to neutral locations and probes at the locations of new distractors) when the probes appeared $200 \mathrm{msec}$ after previews, whereas there was worse detection on old items when the probes followed $800 \mathrm{msec}$ after previews. We discuss the results in terms of visual marking and attention capture processes in visual search.
\end{abstract}

In everyday life, we can be confronted by scenes in which we have to detect a new target among distractors when there are already old distractors in the visual fieldan example being searching for a friend newly arriving along with other passengers on a train when there are other passengers on the platform waiting to get onto the train. How are we able to optimize our search so that we detect the new target (our friend) efficiently? A variety of possibilities exists. We will consider five.

1. Automatic attention capture. One possibility is that our attention is captured automatically by the new stimuli, so that only these items are attended. Studies of our ability to attend selectively to new stimuli indicates that new targets are detected more quickly than targets that are created from a change in an old object and, furthermore, that there are only minor effects of the number of old objects on the efficiency of selecting the new target (see, e.g., Yantis \& Hillstrom, 1994; Yantis \& Jonides, 1984; see Egeth \& Yantis, 1997, for one recent review).

This work was supported by an MRC grant to G.W.H. Correspondence concerning this article should be addressed to G. W. Humphreys, School of Psychology, University of Birmingham, Birmingham B15 2TT, England (e-mail: g.w.humphreys@bham.ac.uk).

Note-This article was accepted by the previous editorial team, headed by Neil Macmillan.
Automatic attention capture by new stimuli could generate efficient search for new targets (Donk \& Theeuwes, 2001).

2. Prioritized attention to new stimuli. A second possibility is that search to new items is optimized not in a passive fashion (by automatic attention capture), but by our adopting an anticipatory set toward the new items, so that attentional priority is given to these stimuli, relative to old distractors already present (see Folk, Remington, \& Johnston, 1992).

3. Temporal grouping. A third suggestion is that efficient search could be based on temporal grouping, contingent on the temporal asynchrony between the onsets of the old and the new displays (Alais, Blake, \& Lee, 1998; Blake \& Yang, 1997; Jiang, Chun, \& Marks, 2002a, 2002b; Lee \& Blake, 1999; Leonards, Singer, \& Fahle, 1996). Coding of the old and the new items into separate temporal groups may enable attention to be selectively allocated to the new stimuli.

4. Allocation of FINSTs. A further possibility relates to the notion of fingers of instantiation (FINSTs), put forward by Pylyshyn and Storm (1988). According to Pylyshyn and Storm, we are able to apply a limited set of FINSTs (about four) as indexes to direct attention to regions of interest. It may be that, by applying FINSTs to old locations, we are able to keep old stimuli out of search when new items appear (although exactly how this might 
be achieved is unclear, since the original idea of FINSTs was to direct attention to potential targets, not away from irrelevant distractors). Alternatively, FINSTs might be applied to a limited number of new stimuli on the basis of the temporal differences between the old and the new items [see (3) above]. These new stimuli then gain attentional priority.

5. Visual marking. A fifth suggestion is that attention to new stimuli can be prioritized, at least in part, by inhibiting old stimuli - a process termed visual marking by Watson and Humphreys (1997). Watson and Humphreys (1997) originally suggested that inhibition could be applied to the locations of old items, so that these items no longer competed so strongly for attention when new items appeared. More recently, evidence has suggested that marking operates also on the basis of color (Olivers \& Humphreys, 2002, 2003; Olivers, Watson, \& Humphreys, 1999) when old and new stimuli are segregated by color as well as by location.

In order to investigate the processes that lead to efficient visual selection of new items, relative to old ones, Watson and Humphreys (1997) adopted a standard search procedure for targets defined by a conjunction of color and form (a blue $H$ among green $H$ s and blue $A$ s). In a preview condition, the distractors in one color (the green $H \mathrm{~s})$ were presented first before the second set of items (the blue $A$ distractors and the blue $H$ target, when present). They found that, in terms of the slopes of the search functions, search in the preview condition was as efficient as that in a single-feature baseline (blue $A$ s and blue $H$ only) and that it was more efficient than the standard conjunction baseline (when all the items appeared together). The new items were prioritized in search. Subsequent studies have demonstrated that the preview benefit is maintained even if the old and the new stimuli do not differ in color (Olivers et al., 1999; Theeuwes, Kramer, \& Atchley, 1998) and that it can occur with up to 15 old and new items (Theeuwes et al., 1998). This last result is interesting because studies of automatic attention capture suggest that this process may be limited to four items or so (Yantis \& Jones, 1991). Similarly, the FINST account holds that only about four locations or so may be indexed (Pylyshyn \& Storm, 1988). The processes underlying efficient preview search have a greater capacity than would be expected from these accounts. Other studies have demonstrated that preview search is disrupted when participants have to perform a secondary task while old items are present (Humphreys, Watson, \& Jolicœur, 2002; Olivers \& Humphreys, 2002; Watson \& Humphreys, 1997). Again, this result does not sit comfortably with the idea of automatic attention capture, since new items then ought to be selected irrespective of the cognitive load prior to their appearance. Instead, it appears that, for optimal search, participants need to actively anticipate new stimuli and/or adopt an active bias against old items.

More direct evidence for a negative bias against old items comes from studies in which probe dot procedures are used to trace the allocation of attention during search tasks. Probe detection has been used in studies of search to provide a measure of where attention is allocated within a display, the inference being that detection is improved when probes appear at attended locations, relative to unattended ones (see Klein, 1988; Müller \& von Mühlenen, 2000). Watson and Humphreys (2000) had participants engage in a preview search task on the majority of trials (76\% of the occasions). On a minority of trials, however, they were cued to discriminate whether a briefly presented probe dot had appeared (the dot appeared just after the occurrence of the new, search stimuli). Watson and Humphreys (2000) found that probes were difficult to detect when they fell at the locations of old distractors, relative to when they fell at the locations of new stimuli. In contrast to this, there was no effect of whether probes fell on old or new items when participants were asked only to take part in a probe detection task. Thus, the variation in probe detection was linked to selection's being prioritized to the new items in the search task. This is an intentional, rather than an automatic, process. Watson and Humphreys (2000) suggested that prioritization in search was based on an intentional bias against old items, which resulted in inhibition of the locations of old items. Due to this inhibition, probes presented at these locations were difficult to detect. Olivers and Humphreys (2002) have recently reported results similar to these, using a procedure in which reaction time (RT) responses were made to probes. RTs to probes were long when they fell at the locations of old, relative to new, items. This cost for probes at old distractor locations was reduced when participants engaged in a secondary task when the previews were presented. This is consistent with inhibition's being reduced under secondary task conditions.

There was one other piece of evidence in Olivers and Humphreys (2002) favoring an inhibitory account based on negative carryover effects across trials. They used a preview task in which the old items differed in color from the new stimuli. On subsequent trials, they presented search displays, without the preview, with elements that had the same color as the stimuli in the prior preview. On these nonpreview trials, RTs were longer, particularly when the earlier preview had not appeared under secondary task conditions (and so may have been subject to stronger inhibition). This negative carryover across trials fits with the idea of color-based inhibition of previews (in addition to any location-based inhibition), which produces longer RTs to stimuli subsequently sharing that color (see also Olivers \& Humphreys, 2003, for further evidence).

Although the results above are consistent with inhibitory processes influencing preview search, it remains possible to argue that the data from probe procedures reflect attentional prioritization to new stimuli, rather than biases against the old items. For example, Watson and Humphreys (2000) did not include a neutral probe condition, so it is possible that the difference between detection at old and new distractor positions was caused by attention being drawn to the new distractors. Against this is Olivers and Humphreys's (2002) finding that perfor- 
mance at old locations improved when the preview appeared under secondary task conditions; it is difficult to see why this should arise on the basis of an attentional capture view (there should only be a decrease for probe detection on less prioritized, new items).

One other problem with the earlier probe studies is that probes were always presented after the new stimuli. It may be that, even if there is inhibition at old locations, this occurs only when attention is drawn to the new items. Inhibition, if present, may be the result of an attentional set to select new items being put into place. It is also possible to apply a temporal grouping account to the data. Once new stimuli are presented and selected as a temporal group, attention may be deprioritized to old items, disrupting probe detection at those locations. To account for negative carryover effects, though, a temporal grouping account would also have to propose that there is inhibition of the old group as part of the segmentation and selection process (see Jiang et al., 2002b).

In the present study, we again used a probe dot procedure to measure the allocation of attention during preview search. We had two aims. One was to rectify some of the earlier problems in comparing neutral, old, and new locations. We did this by representing the old and new stimuli as color changes applied to a grid that occupied all the possible locations at which the probe could appear, with the old and new shapes appearing as outlines superimposed on the grid (see Figure 1). The probe, when present, fell in the empty area between the squares making up either the background grid or the old or new stimuli. Hence, it was equidistant from a contour in all cases, and any masking effects should be equivalent whether the probe fell at an old, a neutral, or a new location (see Cepeda, Cave, Bichot, \& Kim, 1998, for the development of this procedure). This was also verified in the present Experiment 3. In addition, all of the contours present (defining the grid and the old and new shapes) changed in luminance in a random fashion around a level set to be roughly isoluminant across participants (and isoluminant for each participant in Experiment 4). As a consequence, there were, on average, no luminance differences between the contours. Under these conditions, differential masking effects at old, new, and neutral locations are unlikely (an argument added to by the pattern of results found). We ask whether there is worse detection of probes at old locations, relative to new and neutral locations, or whether all the differences reflect an advantage for probes falling on new objects.

The second aim of the study was to assess the time course of attentional allocation by varying the time at which probes appeared, relative to preview and new search displays. This then enabled us to evaluate the mechanisms underlying the preview effect. Previews always appeared for 1,000 msec and were followed immediately by search displays. Experiment 1 established that the standard preview effect would occur in search with the stimuli used here. In Experiment 2, probes were presented 800 and $1,200 \mathrm{msec}$ after the previews (i.e., before and after the new items appeared). We asked whether all the effects were contingent on the appearance of the new items (at $1,200 \mathrm{msec}$ ) or whether differences in probe detection emerged prior to the appearance of the new stimuli (at $800 \mathrm{msec}$ ). Experiment 3 was a control study, undertaken to test whether differences in probe detection at old, neu-

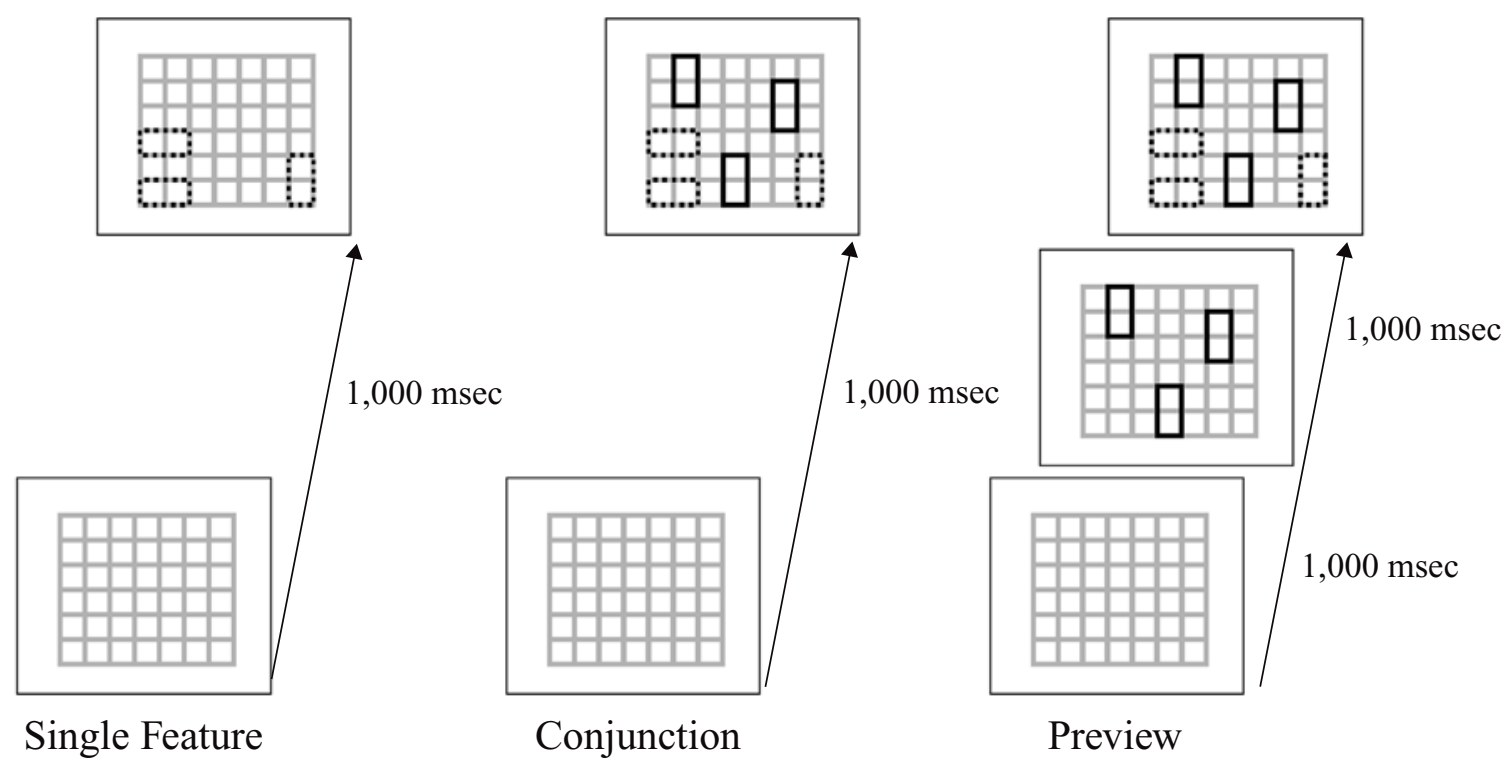

Figure 1. Example displays from Experiment 1 (search task): unbroken line $=$ green; broken line $=$ red. A target-present trial is shown (red vertical). Note that in the actual displays used in the study, the size of the background grid was $22 \times 22$ squares and that the stimuli used in the search task occupied an area of $1 \times 3$ of the background squares. For ease of illustration, we show a grid of just $7 \times 6$ squares and search stimuli $1 \times 2$ squares in area. 
tral, and new locations reflected just the passage of time from the presentation of the old to that of the new items (Experiment 3A) or just the color differences between the contours surrounding the old, neutral, and new locations (Experiment 3B). In Experiment 4, we investigated the time course of attentional allocation before the search displays appeared by presenting probes either 200 or $800 \mathrm{msec}$ after the onset of the preview. The results suggested that early attention to old items was followed by their subsequent inhibition, along with attentional prioritization of the new stimuli. We discuss the data in terms of both inhibitory marking and attentional prioritization of new objects.

\section{EXPERIMENT 1 A Replication of the Standard Search Results}

The stimuli used in the present probe study were somewhat different from those employed previously in experiments on preview search (typically, letters or solid shapes). Experiment 1 was thus conducted to verify that the standard preview benefit would emerge with these stimuli before we proceeded to use them in probe experiments.

\section{Method}

Participants. There were 13 participants ( 6 females and 7 males; age range, 18-34 years), all with either normal or corrected-tonormal vision.

Stimuli. All the stimuli were generated and presented on an IBM PC-compatible Pentium computer driving a super VGA-card and monitor. In this and all the subsequent experiments, the displays were generated by programs written in Turbo Pascal, and the computer recorded all relevant mouse clicks and RTs. The participants sat approximately $50 \mathrm{~cm}$ from the screen, and the experiment was conducted under light-dimmed conditions.

The fixation cross was $0.45^{\circ} \times 0.45^{\circ}$. The stimuli were outline rectangles placed pseudorandomly on a $22 \times 22$ grid, measuring $9.3^{\circ} \times 9.3^{\circ}$ of visual angle (bars covered an area of $1 \times 3$ squares on the grid; $\left.0.42^{\circ} \times 1.27^{\circ}\right)$. The target and distractor bars were placed at random locations on the grid, with the proviso that they were at least $1.2^{\circ}$ apart. The background grid was blue, the old items were green, and the new items were red. The stimuli were tuned to be isoluminant for the experimenter (B.J.S.) by adjusting the color guns of the monitor to the flicker frequency threshold values of the red, green, and blue spectrum against gray. The colors were made to shimmer by randomly changing the RGB values between $-12 \%$ and $+12 \%$ (step size, $1 \%$ ) every $16 \mathrm{msec}$.

Design and Procedure. There were three search conditions, presented in separate blocks. In each condition, the fixation cross appeared alone for $1,000 \mathrm{msec}$, but then remained through the rest of the trial. In the preview condition, the fixation cross was followed by the green vertical distractors for $1,000 \mathrm{msec}$ and then by the search display (red horizontal distractors and a red vertical target, when present). The participants were instructed to focus on the cross throughout the trial. There were also two baseline conditions. In the single-feature baseline, the fixation continued for $2,000 \mathrm{msec}$ (matched to the preview condition), and it was followed by the red shapes only. In the conjunction baseline, all the stimuli (red and green) appeared together simultaneously, after a fixation period of 2,000 msec.

The participants completed one block of trials for each condition in one single session lasting approximately $45 \mathrm{~min}$, with block and condition order counterbalanced across participants. Each block contained 120 trials, with an equal number of target-present and target- absent trials at each display size. There were three display sizes for each condition. In the conjunction baseline, there were 6,10 , and 14 items. In the preview condition, the display sizes were subdivided into preview and search displays, with half the distractors appearing in each (display sizes of $3+3,5+5$, and $7+7$ ). In the single-feature baseline, only half the number of distractors appeared (display sizes of 3, 5, and 7). There were 120 trials in each block, with breaks after each third of the block. The participants received a practice block with a representative sample of trials before the actual experiment started. The participants responded to the presence or absence of the target, a red vertical rectangle. Responses were given with a mouse click: the right button for target present and the left for target absent. After the response, the display disappeared, and a new trial began.

\section{Results}

The mean correct RTs (in milliseconds) are presented in Figure 2, and the mean percentages of errors are given in Table 1. Descriptive statistics for the RT search functions are shown in Table 2. There were no indications of speed-accuracy tradeoffs as a function of condition and display size, and the error data were not analyzed further. The RT data were analyzed by comparing performance in the preview condition against that in each of the baseline conditions. If preview search was affected by the total number of items in the final display, performance ought to match that in the conjunction baseline. If search was affected only by the new red items, performance ought to match that found in the single-feature baseline (see Humphreys et al., 2002).

Preview versus conjunction baseline. RTs were subjected to a three-way repeated measures analysis of variance (ANOVA), with the factors being target presence/ absence, condition (preview vs. conjunction), and display size $(6,10$, or 14 items). All the main effects were significant [target presence/absence, $F(1,12)=6.62$, $p<.05$; condition, $F(1,12)=14.91, p<.01$; display size, $F(2,24)=40.36, p<.001]$. There were reliable two-way interactions between target presence/absence and display size $[F(2,24)=3.89, p<.05]$ and between condition and display size $[F(2,24)=9.08, p<.001]$. The threeway interaction was not reliable $(F<1)$. The effects of display size were larger on the conjunction search task than on preview search (indeed the slopes for preview search were about half those found in conjunction search; see Table 2).

Preview versus single-feature baseline. All of the main effects were again significant [target presence/ absence, $F(1,12)=5.26, p<.05$; condition, $F(1,12)=$ $6.11, p<.05$; display size, $F(2,24)=33.72, p<.001]$. There was one interaction, between condition and display size $[F(2,24)=3.76, p<.05]$. The three-way interaction between target presence/absence, condition, and display size was not reliable $[F(2,24)=1.80, p=.19]$. RTs increased more in the preview condition than in the single-feature baseline, indicating some impact of the old items on search. An inspection of Figure 2 and Table 2 suggests that this effect occurred primarily on absent trials. Taking present trials alone, there was no effect of condition and no condition $\times$ display size interaction (both $F<1$ ). 
(A) Single feature vs. preview

\section{(B) Conjunction} vs. preview
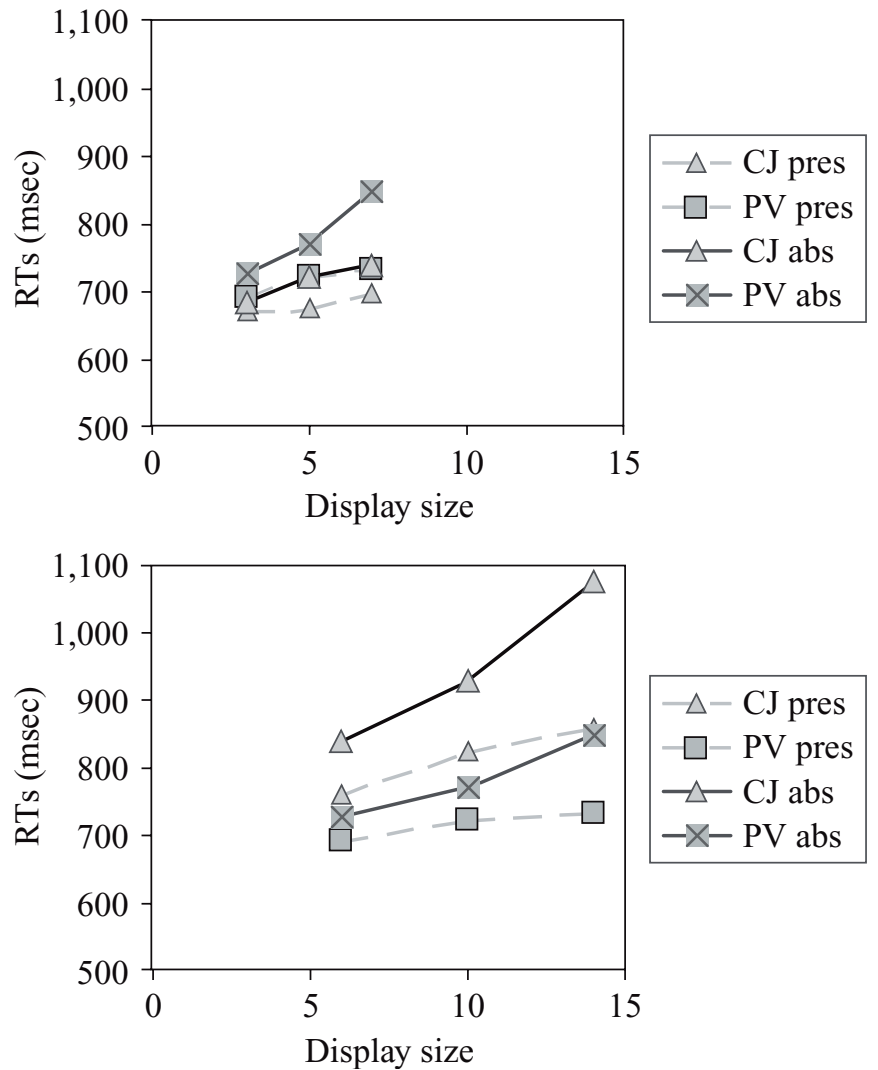

Figure 2. Mean correct reaction times (RTs, in milliseconds) in Experiment 1. (A) The data in the preview (PV) condition are plotted according to the number of items in the new search display (matched to the single-feature $[\mathrm{SF}]$ baseline). (B) The data in the preview condition are plotted according to the number of items in both displays (matched to the conjunction [CJ] baseline).

\section{Discussion}

The data demonstrate a reliable preview advantage in search, relative to the conjunction baseline condition. Slopes for the search functions in the preview condition, relative to the total numbers of items in the final search displays, were about half those observed in the conjunction condition. Thus, under the present circumstances, a preview benefit occurs. It is interesting to note that the benefit was found here with old and new items close to isoluminance and with search displays not strongly defined by a change in luminance (given up to $12 \%$ variations in red-green-blue values taking place every $16 \mathrm{msec}$ or so). Donk and Theeuwes (2001) have argued that a preview benefit does not occur unless the new items are defined by luminance onsets. They used this result to argue that the preview benefit in search is due to attentional capture by the new onsets. There is reason to doubt this conclusion from the present results, although given that isoluminance was not determined for individual participants here, we need to be cautious. In addition, in Donk and Theeuwes, the stimuli were isoluminant with their background, and this may have made search difficult. Here, the stimuli were not isoluminant with the background, but they were close to isoluminance with the grid that defined the locations of the stimuli relative to the background (and brightness levels of individual pixels fluctuated over time; hence, the new items were unlikely to be defined by luminance onsets). It may be that some form of initial figure-ground segmentation is important for the new items to be prioritized for search and that this process is deficient when stimuli are isoluminant with their background. However, given initial

Table 1

Mean Percentages of Errors as a Function of Search Condition, Target Presence/Absence, and Display Size in Experiment 1

\begin{tabular}{lllllll}
\hline & \multicolumn{6}{c}{ Display Size } \\
\cline { 2 - 7 } Condition & 3 & 5 & 7 & 6 & 10 & 14 \\
\hline Single feature & & & & & & \\
Present & 2.2 & 1.9 & 1.4 & & & \\
Absent & 1.7 & 1.7 & 2.5 & & & \\
Conjunction & & & & 1.9 & 1.1 & 3.3 \\
Present & & & & 1.7 & 2.8 & 0.8 \\
Absent & & & & & & \\
Preview & & & & 2.2 & 2.8 & 1.9 \\
Present & & & & 1.1 & 0.8 & 1.4 \\
Absent & & & &
\end{tabular}

Note-Data in the preview condition are presented with the display size stated for the total number of items in the final display. 
Table 2

Slopes (Milliseconds/Item) for the Search Functions in the Single Feature, Conjunction, and Preview Conditions in Experiment 1

\begin{tabular}{lcc}
\hline & \multicolumn{2}{c}{ Slopes Based On } \\
\cline { 2 - 3 } Condition & Items in Display 2 & Items in Displays 1 and 2 \\
\hline Single feature & 7.0 & \\
Present & 13.6 & \\
Absent & & 12.8 \\
Conjunction & & 29.5 \\
Present & & \\
Absent & 10.2 & 5.1 \\
Preview & 30.6 & 15.3 \\
Present & & \\
Absent & & \\
\hline
\end{tabular}

Note-The slopes in the preview condition were calculated using either (1) the display size matched to the items in the new search display (cf. the single-feature baseline) or (2) the display size matched to the total number of items in the final search display (cf. the conjunction baseline).

figure-ground segmentation, we suggest that new onsets may not be crucial.

Although there was a clear preview advantage, preview search was less efficient than in the single-feature baseline. Thus, there was some effect of the old items on search. Primarily, however, this was carried by targetabsent trials. On absent trials, participants may be relatively cautious and sometimes search all the items present in the final display before responding, even under preview conditions (see Chun \& Wolfe, 1996).

\section{EXPERIMENT 2 \\ Analyzing the Time Course of Processing Using a Probe Dot Procedure}

Having established that a preview advantage can occur with the present displays, we sought in Experiment 2 to assess the allocation of attention to the old and new distractors as a function of the time following the onset of the preview displays. As a consequence, the participants were required not only to search for targets (as in Experiment 1) but also to detect whether briefly presented probes occurred. Both Olivers and Humphreys (2002) and Watson and Humphreys (2000) have shown that probe detection varies according to whether participants prioritize the search or the probe detection task. In particular, they found that differences in the detection of probes on old and new distractors occurred only when search was prioritized. To ensure that search was prioritized here, we had the participants make a speeded RT response to the presence or absence of the search target (a red vertical rectangle again), and then they were prompted, on half the trials, to decide whether a probe was present or absent. The probe was present on $50 \%$ of the prompted trials. When present, the probe could fall within the area of an old distractor, within the area of a new distractor, or at a neutral location (within one of the squares of the background matrix). These three events were equally probable. By including a neutral location condition, we aimed to evaluate whether detection was facilitated when probes fell on new stimuli or inhibited when they fell on old distractors. Probes appeared either 800 or 1,200 $\mathrm{msec}$ after the preview display (i.e., $200 \mathrm{msec}$ either before or after the appearance of the new search items). Since the probe always appeared within an area surrounded by contours (in the new, as well as in the old and new, distractor location conditions), and since the contours were close to isoluminance with one another and randomly varying in luminance, differences in masking across the probe conditions should be relatively minor. We reasoned that, if there was only (1) attentional capture by new stimuli, (2) attentional prioritization to new stimuli, or (3) temporal segmentation of old and new items, there should be minimal differences in detection for probes presented before the onset of the search displays (800 msec after the preview), but differences should emerge for probes following the search displays (at the 1,200 -msec interval). Detection should be facilitated for probes that fall on new distractors, and detection of probes on old distractors and at neutral locations should be equated. On the basis of a FINST account, where FINSTs may be allocated to the old items, we might expect somewhat different results. Here, probe detection on old items should be relatively good, at least prior to the appearance of any new stimuli (i.e., with an 800 -msec interval following onset of the preview). However, if there is inhibition of old items, probes on these old items may be more difficult to detect than probes at neutral locations. Indeed, if inhibition takes place before the new stimuli appear, differences may occur even with probes occurring $800 \mathrm{msec}$ after the previews (note that Watson \& Humphreys, 1997, demonstrated that a preview benefit was present when search displays followed about $700 \mathrm{msec}$ or so after previews).

\section{Method}

Participants. Twenty-four participants took part (14 females and 10 males; ages, 17-52 years). All had either normal or correctedto-normal vision.

Stimuli. The stimuli for the search task were the same as those in Experiment 1, except that only one display size was used $(5$ old +5 new items). The probe was a gray dot $0.09^{\circ}$ in diameter, which appeared for $50 \mathrm{msec}$. The red-green-blue values used for the background matrix and the search items were the same as those in Experiment 1 (set to isoluminance by flicker fusion, for one experimenter).

Design and Procedure. Only the preview search condition was used, and this was the same as that in Experiment 1, except that there were 480 trials. The search target was present on half of these trials and absent on the remainder. The participants were prompted to make a decision about the probe (was a dot present?) on half the trials (half target present, half target absent), and the probe dot was presented on $50 \%$ of the prompted trials (equally often on targetpresent and target-absent trials). When present, the probe appeared on an old distractor, on a new distractor, and at a neutral location equally often, and it appeared either 800 or 1,200 msec after the appearance of the preview (i.e., there were 20 probe trials per duration in each of the conditions in which the probe was present). With an 800 -msec interval between the preview and the probe, probes in the new distractor condition fell at locations that would subsequently be occupied by new distractors in search displays. The participants were asked to concentrate on the search task and to respond whether the target was present or absent as quickly and accurately as they 
could. They were then asked to decide whether a probe occurred by means of a computer prompt (was a dot present or absent?). Unspeeded responses were made by mouse click (left $=$ dot absent). The next trial began 1,000 msec later. Probe conditions were randomized within a block of trials. An example trial is shown in Figure 3 .

\section{Results}

Search task. Since we used a constant display size here, we could not analyze "standard" search functions. Nevertheless, the data were broken down according to whether the target was present or absent and according to whether the probe was present or absent on that trial. The search RT data were analyzed in a three-factor ANOVA, with the factors being target presence/absence, time of probe ( 800 or $1,200 \mathrm{msec}$ after the preview), and probe condition (whether the probe was absent, present on an old distractor, present on a new distractor, or present in the background). There were reliable effects of target presence/absence $[F(1,22)=10.35, p<.01]$ and time of probe $[F(1,22)=8.09, p<.01]$. The effect of probe condition was not reliable $[F(3,66)=1.26, p>.05]$. There was one reliable interaction, between time of probe and probe condition $[F(3,66)=5.31, p<.01]$. The mean correct RTs are plotted in Figure 4. Table 3 gives the mean percentages of errors.
The interaction between time of probe and probe condition was broken down by analyzing the data at the two time intervals separately. When the probes appeared $800 \mathrm{msec}$ after the onset of the preview, there was no reliable effect of probe condition $[F(3,66)=1.25, p>$ $.05]$. When the probes appeared 1,200 $\mathrm{msec}$ after the onset of the preview, there was a reliable effect of probe condition $[F(3,66)=5.76, p<.001]$. RTs were shorter when no probe occurred than when the probe occurred on an old distractor, on a new distractor, or in the background $[t(23)=-3.71,-4.26$, and -2.96 ; all $p$ s $<.01]$. When the probe appeared, there was no effect of its location on an old or new distractor or in the background (all $t \mathrm{~s}<1$ ).

An inspection of Table 3 reveals that there was no speed-accuracy tradeoff.

Probe task. Probe dot detection, as a function of the interval between the preview and the probe, is shown in Figure 5. There were false positive responses to probes on $5.67 \%$ of the trials with an 800 -msec interval and on $5.1 \%$ of the trials with an interval of $1,200 \mathrm{msec}$ between the preview and the probe.

The probe detection data for trials on which probes were present were subject to a repeated measures ANOVA with time ( 800 vs. $1,200 \mathrm{msec})$ and condition (probe at

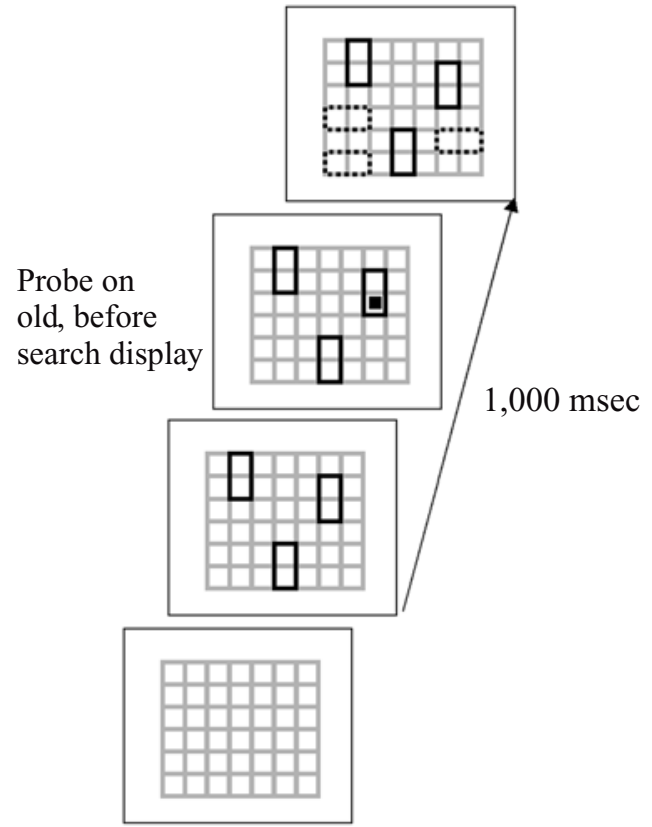

Probe SOA $800 \mathrm{msec}$ (before new search display)

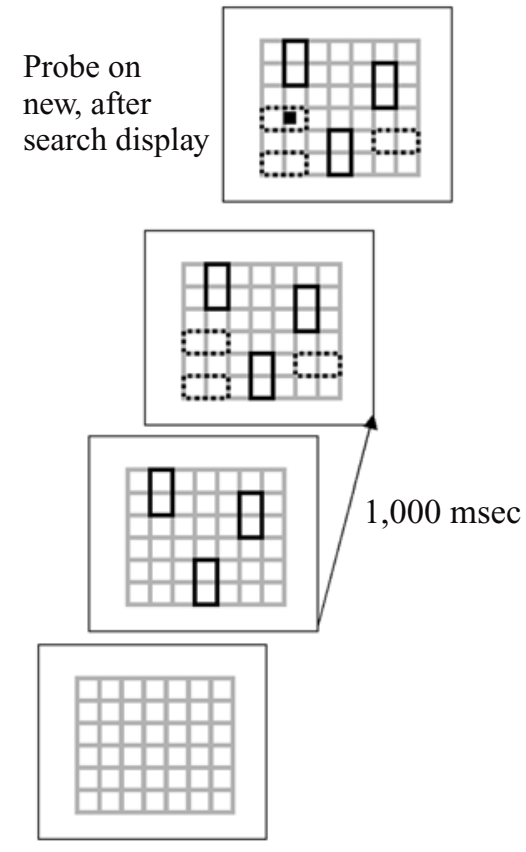

Probe SOA 1,200 msec

(after new search display)

Figure 3. Example displays from the probe condition (target absent in the search display). (A) Probe at $800 \mathrm{msec}$ ( $200 \mathrm{msec}$ before the search display); (B) probe at 1,200 $\mathrm{msec}$ (200 msec after the search display). For panel A, the probe here is shown on an old distractor prior to the search display. For panel B, the probe is depicted on a new distractor after the search display. Probes could also appear at neutral (unoccupied) locations. 

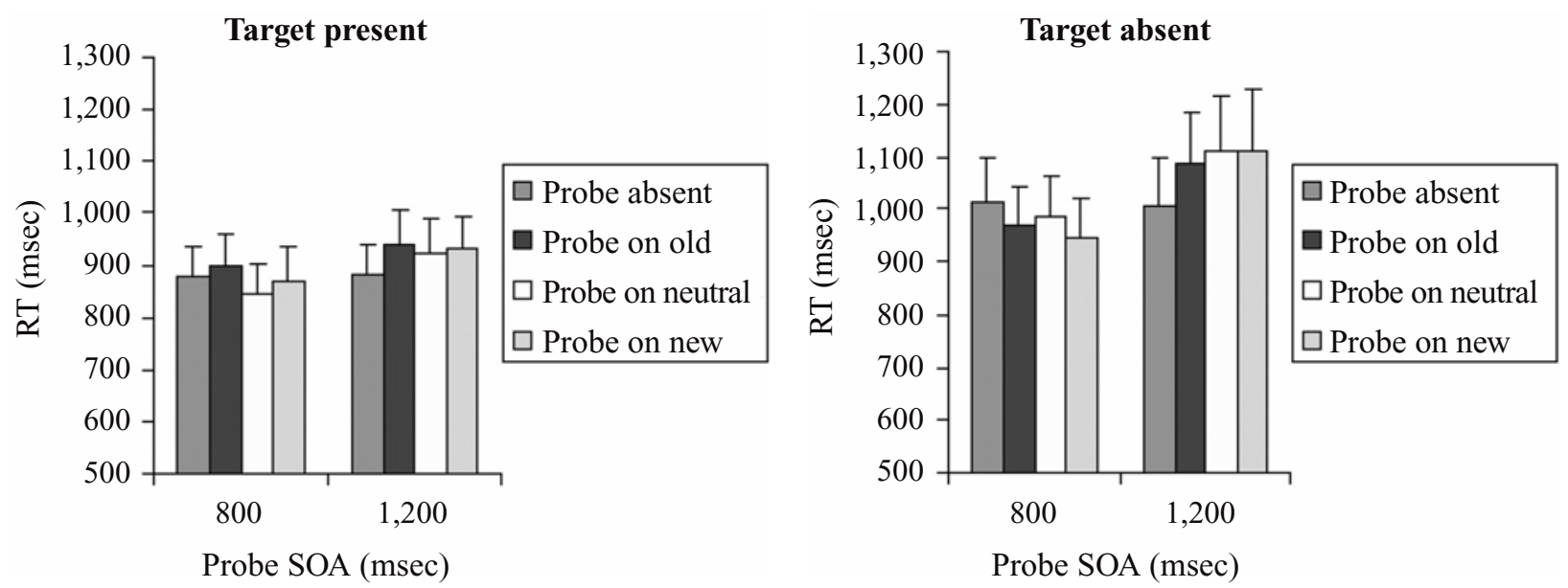

Figure 4. Mean correct reaction times (RTs, in milliseconds) on search trials in Experiment 2, as a function of the probe presentation time and location. Bars indicate standard errors.

old, new, or neutral location) as the factors. There were reliable main effects of both time $[F(1,23)=62.05, p<$ $.001]$ and condition $[F(1,23)=6.15, p<.01]$. The interaction did not approach significance $(F<1)$.

To assess the effects of condition, separate planned ANOVAs were conducted comparing detection on (1) old distractors versus neutral locations, (2) old versus new distractors, and (3) new distractors versus old locations. Time was maintained as a factor, to assess whether there were any indications of differential detection of probes at the two intervals.

Old distractors versus neutral locations. There were main effects of time and condition $[F(1,23)=60.23$ and 6.49 , both $p$ s $<.025$ ] but no interaction $(F<1)$. Probes at neutral locations were detected more accurately than probes that fell on old distractors. Detection was also better with the 800-msec than with the 1,200-msec interval.

Old versus new distractors. The effects of time and condition were again significant $[F(1,23)=48.55$ and 9.45 , both $p$ s $<.01]$. The interaction was not reliable
$(F<1)$. Probes on new distractors were detected better than probes on old distractors. Detection was better with the shorter interval between the preview and the probe.

New distractors versus neutral locations. There was an overall effect of time $[F(1,23)=51.68, p<.001]$ but not condition $[F(1,23)=1.30, p>.05]$. The time $\times$ condition interaction also was not reliable $[F(1,23)=$ 1.45]. However, an inspection of Figure 3 indicates that targets on new distractors tended to be identified better at the longer interval (at 1,200 msec: error rate on new $=$ .534 vs. neutral $=.596$ ), whereas (if anything) the reverse held at the shorter interval (error rate on new $=$ .268 and on neutral $=.260$ ).

\section{Discussion}

Relative to the search data from Experiment 1, performance was somewhat worse here (RTs were longer). This may reflect a general cost from having to perform two tasks at once (probe detection as well as search). There was also some suggestion that probe detection af-

Table 3

Mean Percentages of Errors in the Search Tasks in Experiments 2-4 as a Function of Target Presence, Probe Presence, Interval, and Location

\begin{tabular}{|c|c|c|c|c|c|c|c|c|}
\hline \multirow[b]{2}{*}{ Interval } & \multicolumn{4}{|c|}{ Target Present } & \multicolumn{4}{|c|}{ Target Absent } \\
\hline & No Probe & $\begin{array}{l}\text { Probe } \\
\text { on Old }\end{array}$ & $\begin{array}{c}\text { Probe } \\
\text { on Neutral }\end{array}$ & $\begin{array}{l}\text { Probe } \\
\text { on New }\end{array}$ & No Probe & $\begin{array}{l}\text { Probe } \\
\text { on Old }\end{array}$ & $\begin{array}{c}\text { Probe } \\
\text { on Neutral }\end{array}$ & $\begin{array}{c}\text { Probe } \\
\text { on New }\end{array}$ \\
\hline \multicolumn{9}{|c|}{ Experiment 2 (Preview) } \\
\hline Preview at $800 \mathrm{msec}$ & 0.9 & 0.8 & 0.8 & 0.7 & 0.8 & 1.2 & 0.9 & 0.7 \\
\hline Preview at $1,200 \mathrm{msec}$ & 0.8 & 0.6 & 1.0 & 0.8 & 0.8 & 0.9 & 0.6 & 0.7 \\
\hline \multicolumn{9}{|c|}{ Experiment 3B (Conjunction) } \\
\hline Preview at $800 \mathrm{msec}$ & 1.7 & 1.6 & 1.8 & 1.7 & 1.6 & 1.1 & 1.5 & 1.4 \\
\hline Preview at $1,200 \mathrm{msec}$ & 1.9 & 1.8 & 1.8 & 1.9 & 1.5 & 1.4 & 1.6 & 1.5 \\
\hline \multicolumn{9}{|c|}{ Experiment 4 (Preview) } \\
\hline Preview at $200 \mathrm{msec}$ & 1.2 & 0.8 & 1.0 & 1.0 & 1.2 & 1.0 & 0.8 & 0.6 \\
\hline Preview at $800 \mathrm{msec}$ & 0.9 & 0.9 & 1.2 & 1.2 & 1.4 & 0.6 & 1.0 & 0.9 \\
\hline
\end{tabular}




\section{Experiment 2}

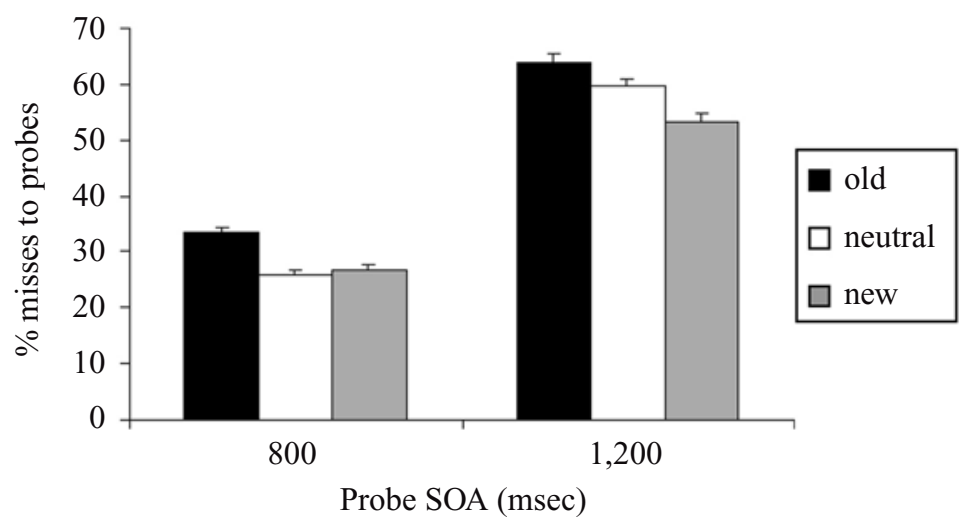

Figure 5. Percentages of misses to probes in Experiment 2 (preview search, stimulus onset asynchronies [SOAs] of 800 and 1,200 msec). Bars indicate the standard errors.

fected search performance, when the probes appeared after the onset of the search display (with a $1,200-\mathrm{msec}$ interval following the onset of the preview). In this condition, search RTs were longer when the probe was present, relative to when it was absent. This lengthening of search RTs would have occurred if the probe competed for attention with the shapes in the search display. Nevertheless, when the probe was present, performance on the search task was not significantly affected by whether the probe fell at an old, a new, or a neutral location. There was also no difference between probe-present and probeabsent trials when the probe appeared after $800 \mathrm{msec}$ (i.e., before the onset of the search display). As we will discuss below, differences in probe detection itself, as a function of the probe's location, occurred at both probe intervals.

The largest effect on probe detection was that performance was better when there was a short interval between the preview and the probe $(800 \mathrm{msec})$ and when there was a longer interval $(1,200 \mathrm{msec})$ : an overall effect of $30.4 \%$. We again attribute this to competition between the probe and attention to the search display. Not only did the presence of the probes slow search (see above), but also the appearance of the search displays competed with attention to probes, decreasing their detection irrespective of whether probes fell on old distractors, on new distractors, or at neutral locations.

In addition to this overall effect of probe presentation time, there were effects of probe location. Probes were relatively difficult to detect when they fell on old distractors, relative to when they fell at neutral locations or on new distractors, and this held across both preview-probe intervals. This is consistent with old distractors being inhibited. There was also a tendency for detection to improve when probes appeared on new distractors, as compared with neutral locations, although this (naturally) was apparent only at the 1,200-msec interval (there were no new items present when probes appeared after $800 \mathrm{msec}$ ).
Hence, there is some suggestion of attention being prioritized to the new items, but it was not overwhelming. Note that these effects are unlikely to reflect differences in the probability of the probe's appearing at any particular location across the three position conditions. It is the case that the probe was considerably more likely to appear within a cell of an old or a new object than within a neutral location in the background grid (there were 454 empty locations in the background grid vs. 15 filled with old stimuli and 15 with new), but detection then ought to have been higher for probes that fell at occupied locations than for probes at neutral locations. This was not the case when probes fell on old distractors.

The effects at the $800-\mathrm{msec}$ interval are interesting, since they run counter to several of the competing accounts of the preview advantage in search. In particular, no effects on probes appearing prior to new stimuli are expected by any of the following accounts, all of which assume that appearance of new items is crucial: (1) capture of attention by new objects (Donk \& Theeuwes, 2001), (2) prioritized attention to new objects (Folk et al., 1992), and (3) temporal segmentation of new and old stimuli (Gibson \& Jiang, 2001).

In addition, the FINST account (Pylyshyn \& Storm, 1988) holds that FINSTs fix attention to stimuli, and so we might expect that probes would be relatively easy to detect if they appeared on old items, relative to the background, prior to the appearance of new items. We found the opposite. The data are consistent with an inhibitory bias away from old items in the search task, which may operate even before new stimuli appear (see Watson \& Humphreys, 1997).

However, the difference in detection between probes on the old distractors and probes on new distractors and at neutral locations was quite small $(8.6 \%$ and $6 \%$, respectively, averaged across preview-probe intervals). Watson and Humphreys (2000) reported larger differences between probes on old and new stimuli in their 
study. One reason for this disparity is that Watson and Humphreys (2000) selected probe durations for individual participants to ensure that performance remained in a sensitive range. In contrast, we employed a single probe duration across participants, with the danger that ceiling or floor effects could enter into performance. Nevertheless, we still found reliable differences in probe detection across the conditions.

\section{EXPERIMENT 3 \\ Probe Detection Alone and Probe Detection in Conjunction Search}

Although the data fit with there being an inhibitory component in preview search, other accounts of the probe detection data are possible. One account is that differences in detection at old, neutral, and new locations are unrelated to preview search but simply reflect temporal differences between the stimuli. For example, after $800 \mathrm{msec}$ or so, the novelty of the preview stimuli may simply fade, and this alone may make probes difficult to detect at these locations. Another possibility is that any differences are caused by the contrasting colors of the contours surrounding the old, neutral, and new locations (green, blue, and red, respectively). Either there may be differential masking by the different colors, or, in search, participants may prioritize the red items when attempting to select the target (a form of attentional guidance through color, although it is not then clear why probes are more difficult to detect at old [green] rather than at neutral [blue] locations). To test these alternative possibilities, we conducted Experiment 3. In Experiment 3A, we presented the same displays as those in Experiment 2, but this time the observers did not have to search for a new target stimulus and, instead, were asked only to perform the probe detection task. If the differences in probe detection are due solely to the temporal intervals between the stimuli, we should expect results here similar to those we observed earlier. Both Olivers and Humphreys (2002) and Watson and Humphreys (2000) examined this prioritize the probe task and found no differences in probe detection across new and old items, suggesting that differences reflected processes operating in the preview search task. This was tested again here.

In Experiment 3B, we had observers carry out a conjunction search task (where the red and the green distractors appeared simultaneously) along with a probe detection task. If there are effects due to color prioritization, probes on red distractors should be easier to detect than those on green distractors. Watson and Humphreys (2000) also evaluated probe dot detection in a conjunction version of their task and found reduced differences between detection on distractors of different colors, relative to when the distractors appeared separately in the preview and the search displays. Experiment 3B assessed whether the same would hold with the present displays.

\section{EXPERIMENT 3A \\ Prioritize the Probe}

\section{Method}

The method was exactly the same as that in Experiment 2, except that the participants were never asked to search for a target red vertical shape but only performed the probe detection task. There were 14 participants ( 10 females and 4 males; age range, 18-24 years), who took part for course credits. All had either normal or correctedto-normal vision.

\section{Results}

Figure 6 gives the mean percentages of misses to probes appearing 800 and 1,200 msec after the presentation of

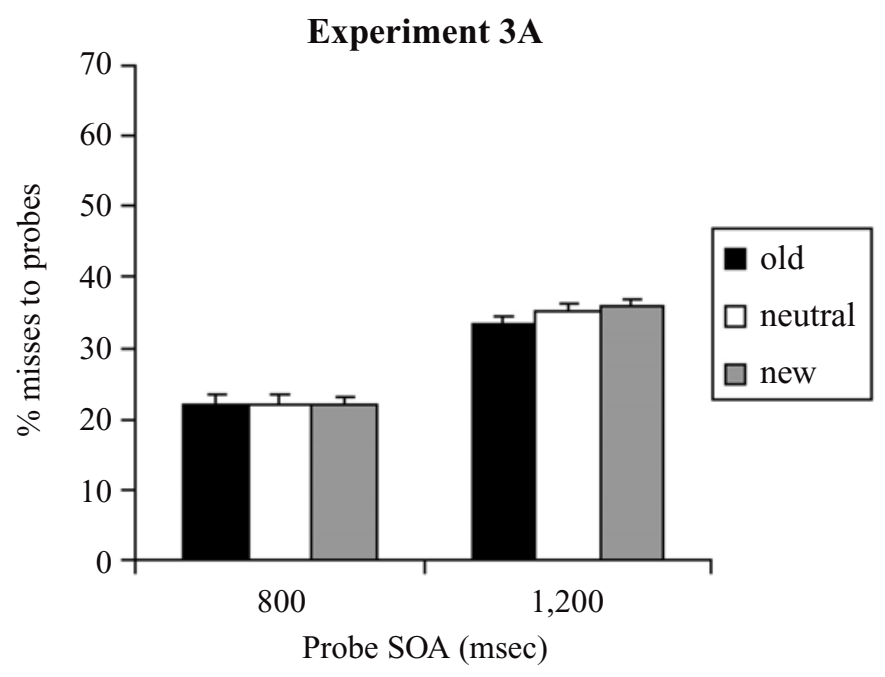

Figure 6. Percentages of misses to probes in Experiment 3A (prioritize the probe, stimulus onset asynchronies [SOAs] of 800 and 1,200 msec). Bars indicate the standard errors. 
the preview. False positive responses were made on $1.7 \%$ of the trials. An ANOVA conducted on the miss data revealed a significant main effect of time $[F(1,13)=55.75$, $p<.001]$ but no effect of condition $[F(2,26)=1.04, p>$ $.05]$ and no reliable interaction $[F(2,26)=2.28, p>.05]$.

\section{Discussion}

There were two interesting findings. The first is that there were no reliable differences as a function of whether probes fell at old, neutral, or new locations. This replicates the prior findings of Olivers and Humphreys (2002) and Watson and Humphreys (2000), that differences in probe detection shown when the probe task is embedded in the context of preview search disappear when the probe task is prioritized. This indicates that the effects are not due to the temporal properties of the displays alone (which were matched to those previously used), nor are the effects due to differential masking from the different-colored surrounding contours (since masking effects should have merged here too). We suggest instead that differences in probe detection reflect a bias in selection adopted in the search task, against old distractors and favoring new items. This bias is carried over to probe detection and leads to an increased miss rate for probes presented on old distractors.

The second result to note is that, as in Experiment 2, there was an overall cost for detecting probes that followed the presentation of the second display (probe duration, 1,200 $\mathrm{msec}$ ), as compared with probes that came after the preview but before the second display (probe duration, $800 \mathrm{msec}$ ). This suggests that at least part of this effect occurred because probes appearing at a stimulus onset asynchrony (SOA) of 1,200 msec came soon after there had been a substantial change in the display. Probes may subsequently have been difficult to detect because their onsets were masked by the prior change, because some resources were drawn to the new stimuli even though they were irrelevant to the task at hand, or because the participants temporarily inhibited any action (including orienting to a probe), in order to ensure that responses would not be made to the (irrelevant) new shapes. Note, however, that the magnitude of the effect was smaller here than in Experiment 2 (about 12\% vs. $30 \%$ ). Thus, even if there was some degree of automatic cost associated with the occurrence of the new stimuli (in Experiment $3 \mathrm{~A}$ ), this effect was exacerbated when the participants were set to prioritize the new display for search (in Experiment 2).

\section{EXPERIMENT 3B Probe Detection in Conjunction Search}

\section{Method}

The method was again the same as that in Experiment 2, except that the participants always conducted a conjunction search task in which the red and the green shapes appeared simultaneously. The red and the green shapes were presented after a 2 -sec period of fixation, with the first $1 \mathrm{sec}$ tied to the fixation period in the preview condition and the second to the preview duration. As in the preview condition, the appearance of the probe dot was tied to the second interval. The dot appeared either $800 \mathrm{msec}$ into the interval (prior to the presentation of the search display) or 1,200 msec after the start of the interval (i.e., $200 \mathrm{msec}$ after the appearance of the search display). There were 14 participants ( 9 females and 5 males; age range, 18-24 years), who took part for course credits, all with either normal or corrected-to-normal vision.

\section{Results}

The mean RTs in the search task are presented in Figure 7. The mean percentages of misses of probe dots are given in Figure 8 . The rate of false positive responses to probes was $4.7 \%$.

Search task. The data were analyzed in the same way as the results from Experiment 2, to assess for effects of the probe on the primary visual search task. There were reliable effects of target presence/absence $[F(1,13)=$ $127.56, p<.001]$, time of probe $[F(1,13)=5.89, p<$ $.05]$, and probe condition $[F(3,39)=5.72, p<.01]$.
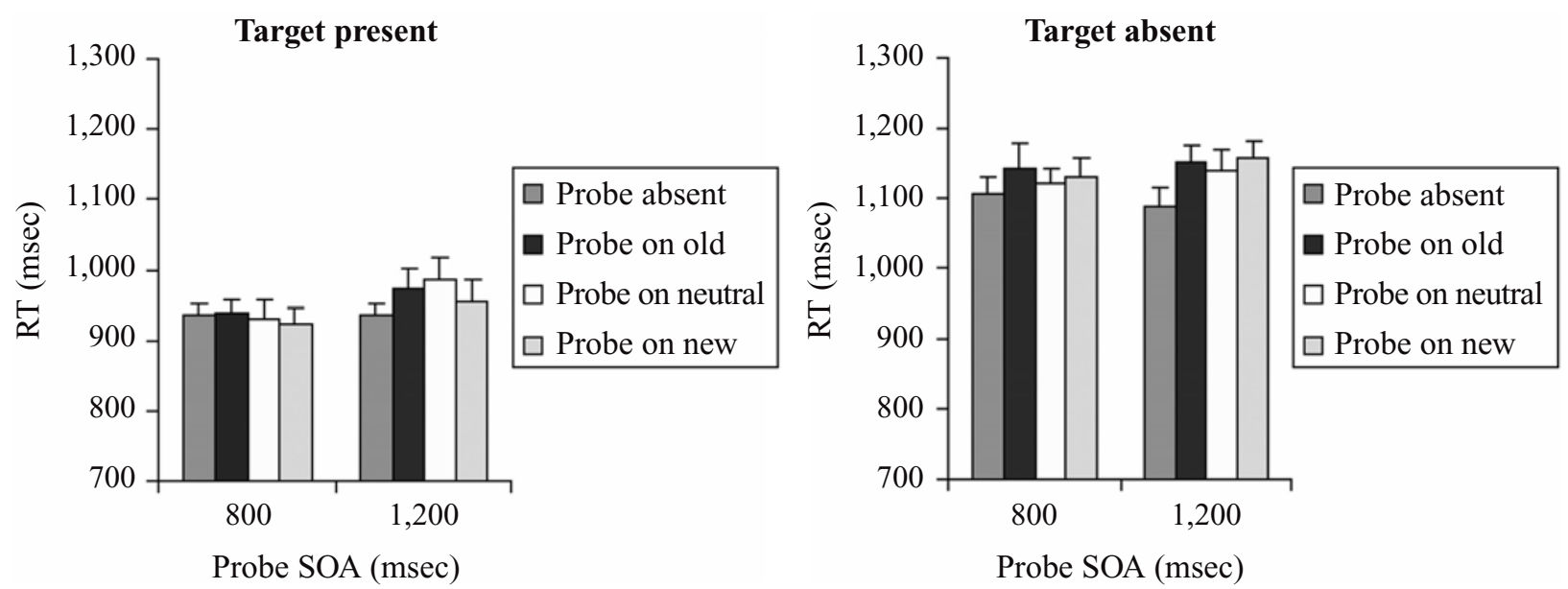

Figure 7. Mean correct search reaction times (RTs, in milliseconds) in Experiment 3B (conjunction search), as a function of the time of probe presentation and probe location. Bars indicate one standard error. 


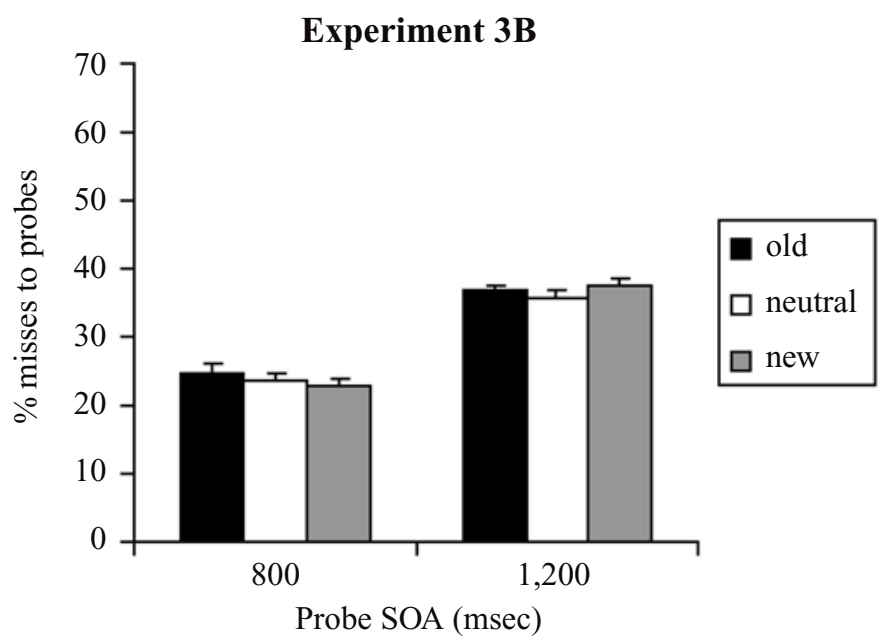

Figure 8. Percentages of misses to probes in Experiment $3 B$ (conjunction search, stimulus onset asynchronies [SOAs] of 800 and $1,200 \mathrm{msec})$. Bars indicate the standard errors.

There were also two reliable interactions, between target presence/absence and probe condition $[F(3,39)=3.35$, $p<.05]$ and between time of probe and probe condition $[F(3,39)=4.98, p<.01]$.

The target presence/absence $\times$ probe condition interaction was analyzed with the data averaged across time. On target-present trials, there was no effect of probe condition $[F(3,39)=1.74, p>.05]$. On target-absent trials, there was an effect of probe condition $[F(3,39)=9.23$, $p<.01]$. RTs were shorter when there was no probe than when the probe fell at old, neutral, or new locations $[t(14)=-3.23,-5.21$, and -3.97 ; all $p$ s $<.01]$. There was no effect of probe location when probes were present (all $t \mathrm{~s}<1$ ).

The interaction between time of probe and probe condition was analyzed in a similar fashion, averaging across target presence/absence. When the probes appeared $800 \mathrm{msec}$ after fixation, there was no effect of probe condition $[F(3,39)=1.80, p>.05]$. When the probes appeared $1,200 \mathrm{msec}$ after fixation, there was an effect of probe condition $[F(3,39)=22.52, p<.01]$. RTs were again shorter when there was no probe than when the probe appeared at old, neutral, and new locations $[t(14)=-7.17,-5.93$, and -5.32 ; all $p$ s $<.01]$. Probe location had no effect on trials in which probes were present (all $t \mathrm{~s}<1$ ).

There were relatively few errors and no evidence of a speed-accuracy tradeoff (see Table 3).

Probe task. There was an effect of probe interval $[F(1,13)=110.40, p<.001]$, but no effect of whether the probe fell at an old (green distractor), neutral, or new location (red distractor; $F<1$ ). The interaction did not approach significance $[F(2,26)=1.42, p>.05]$.

\section{Discussion}

The results in the probe task were similar to those when the participants prioritized the probe (Experiment $3 \mathrm{~A}$ ):
Detection fell when the probes appeared after the search display had been presented, but there was little effect of whether the probe fell on a green or a red distractor (equivalent to the old and the new stimuli in the preview condition). This confirms that differences in probe detection in the preview condition were not due to differential masking from the two types of distractors (see also Experiment 3A). There was also little difference between the detection of probes on distractors and on neutral areas of the display. There have been several previous investigations of probe dot detection in conjunction search tasks (e.g., Klein, 1988; Müller \& von Mühlenen, 2000; Wolfe \& Pokorny, 1990). In general, these studies have indicated that probes are difficult to detect when they fall on distractors, as compared with when they fall at an unoccupied location, at least when search items remain in the display when the probes appear. The comparison between occupied and unoccupied locations may be inflated by differential masking effects, but there remain greater costs for probes on distractors under serial search conditions than when probes fall on distractors that can be discriminated relatively easily from targets (e.g., when the target can be distinguished from the distractor on the basis of a salient feature difference; Müller $\&$ von Mühlenen, 2000). This difference, between detection under easy and difficult search conditions, has been taken as evidence of inhibition of return (IOR) in conjunction search, with attention being biased against distractors that were selected but then rejected. However, in those studies, probes have been presented following the search response, when it can be assumed that search has been completed. In the present experiment, the probes appeared either prior to or relatively soon after the presentation of the search display, and in the latter case, we can assume that search was engaged on the stimuli in the search task when the probes appeared. It may be, then, that there was a tradeoff between the probes appearing 
on distractors that were currently being attended and the probes appearing on distractors that had been selected and rejected (with detection being good and poor, respectively, as compared with when the probes fell at neutral locations). The net effect may be no difference in detection for probes at neutral locations and probes that fall on distractors.

As in Experiments 2 and $3 \mathrm{~A}$, we again found that probes were more difficult to detect when they appeared after the search display $(1,200$-msec interval) than when they appeared before ( 800 -msec interval), perhaps because there was an automatic capturing of attention by the new stimuli on at least some trials or because resources were shared with the search task. Evidence for some sharing of resources across probe detection and search is indicated by the lengthening of search RTs when the probe appeared after 1,200 $\mathrm{msec}(200 \mathrm{msec}$ after the presentation of the search display). RTs in the search task were made longer when the probe was present, relative to when no probe was presented. Unlike in Experiment 3A, any effect of the search display on probe detection is unlikely to have reflected response suppression, since the participants here had to search, rather than ignore (suppress their response to), the presentation of the red and green shapes. However, even though the effect of the temporal interval on probe detection was highly reliable, it remained quite small in magnitude (a $13 \%$ difference). The larger effect of the interval, in Experiment 2, may thus have occurred because the participants were prioritizing their attention for the search display in that study, and more so than was the case here. This may come at the expense of detecting other stimuli when the search display appears.

Finally, as in Experiment 2, we note that there was no effect of probe location on search RTs (when the probe was present). Although there was some slowing of search, presumably because probes were sometimes momentarily attended, this was general across the probe location conditions.

\section{EXPERIMENT 4 Tracking Attention to Previews}

In Experiments 2 and 3, we examined probe detection under conditions in which the preview had already been in the field for some time $-800 \mathrm{msec}$ or longer. Watson and Humphreys (1997) showed that the preview effect itself weakened in strength when previews appeared for shorter durations (e.g., below $300 \mathrm{msec}$ ). With shorter durations, the preview benefit may be reduced for several reasons. One possibility is that short durations do not allow a sufficiently long time to consolidate a memory representation of old items that may be critical to these stimuli's subsequently being ignored in search. Another possibility is that shorter durations are insufficient to enable inhibition to be applied. In Experiment 4, we presented probes $200 \mathrm{msec}$, as well as $800 \mathrm{msec}$, after previews in order to examine whether evidence for inhibition may be eradicated at the short, but not the longer, interval.
Relevant to this study are experiments in which preview search has been examined under dual-task conditions. Here, it has been consistently found that the preview benefit is reduced when participants perform a secondary task when the old items are present (Humphreys et al., 2002; Olivers \& Humphreys, 2002; Watson \& Humphreys, 1997). Humphreys et al. (2002) manipulated both the modality of the secondary task (which was either visual or auditory) and its onset relative to the presentation of the preview (the secondary task began at the onset of the preview, or it began after the preview had been present for $1 \mathrm{sec})$. The auditory secondary task that began at the start of the preview disrupted preview search. However, when the start of the auditory task was delayed relative to the preview, no disruptive effect occurred. In contrast, a visual secondary task disrupted the preview benefit in both the immediate and the delayed conditions. These results suggest that observers may initially need to attend to the preview, perhaps to construct a temporary representation of the stimuli. This process is affected by both visual and auditory secondary tasks. Subsequently, the representation may be inhibited, a process that may be modality specific and, hence, affected only by the visual secondary task. Following these findings, it is possible that a different pattern of probe dot detection may be expected as the time between the preview and the onset of the probe is varied. For example, if attention is locked to the old items as the preview is being encoded, there may be good detection of probes that fall on the old items when there is a short preview-probe interval. At the longer interval, however, we may expect detection at old locations to decrease (see Experiments 2 and 3).

\section{Method}

There were 8 participants, 5 males and 3 females, between 17 and 28 years of age. All had either normal or corrected-to-normal vision.

The procedure was the same as that in Experiment 2, with the following exceptions. First, before the search task began, each participant took part in a flicker fusion procedure in which the red, blue, and green colors were matched to isoluminance with the gray background. This was done to ensure that, for each individual, there were minimal brightness differences between the mean red, green, and blue values that made up the shapes and the background matrix (note also that the values changed by up to $12 \%$ randomly for each pixel every $16 \mathrm{msec}$, too). Second, there were 960 trials for each individual. The participants were queried about the presence of a probe on 480 trials, and the probe was present on 240 trials (120 with a preview-probe interval of $200 \mathrm{msec}$ and 120 with a previewprobe interval of $800 \mathrm{msec}$; there were 40 trials in each probe location condition at each interval).

\section{Results}

Search task. The mean search RTs are presented in Figure 9. There were reliable main effects of target presence/absence and time of probe $[F(1,7)=6.51$ and $28.21, p<.05$ and .01 , respectively]. In this case, there was no effect of probe condition $(F<1)$ and no further interactions. RTs were longer on target-absent than on target-present trials, and RTs were longer when probes appeared $800 \mathrm{msec}$ after the preview than when they ap- 

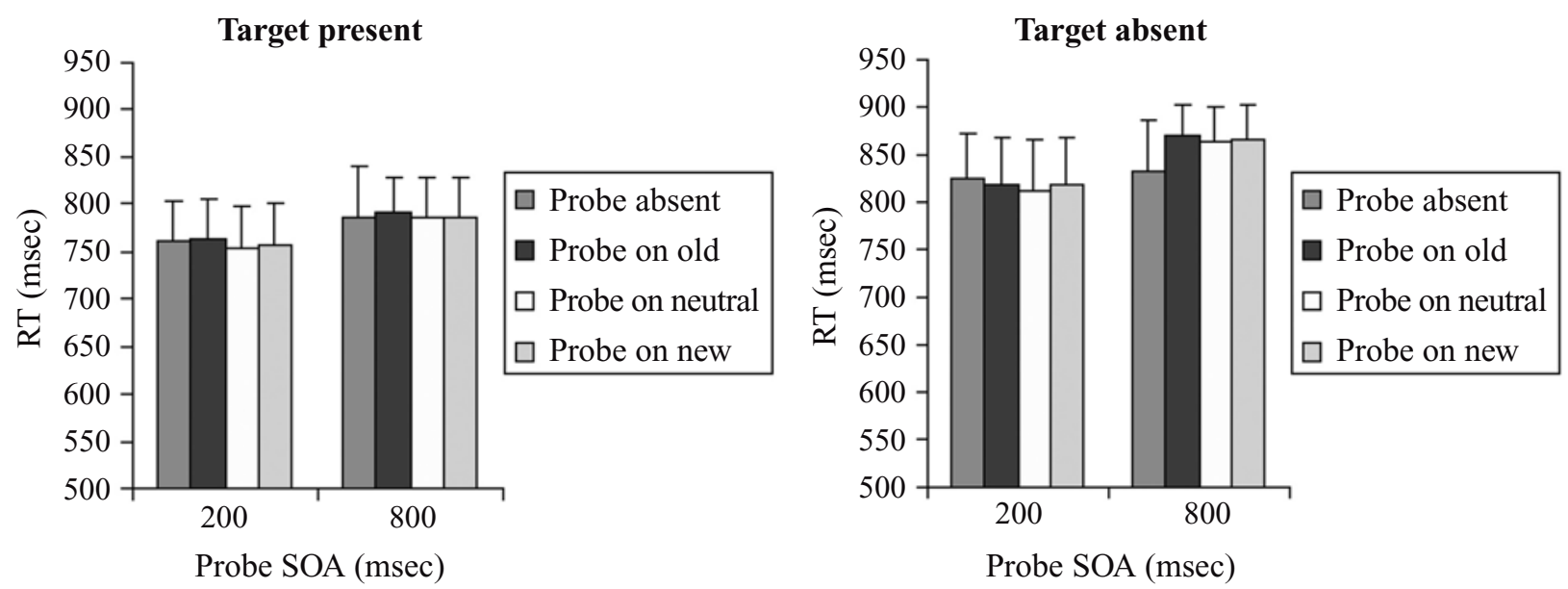

Figure 9. Mean correct search times in Experiment 4 (preview condition), as a function of the time to the presentation of the probe and the probe's location. Bars indicate one standard error.

peared $200 \mathrm{msec}$ after preview onset. There were low error rates and no evidence of a speed-accuracy tradeoff.

Probe task. The mean percentages of miss responses to probe dots, for each preview-probe interval, are given in Figure 10. There were 1.9\% false positive responses (on probe-absent trials). The miss rates were analyzed in a two-factor repeated measures ANOVA with probe SOA and probe location (probe at old, new, or neutral locations) as the factors. There was a trend for more errors at the shorter SOA $[F(1,7)=4.38, p<.10]$, but there was no overall effect of probe location $(F<1)$. There was, however, a probe SOA $\times$ location interaction $[F(1,7)=$ $7.62, p<.01]$. At the 200 -msec interval, there were fewer misses to probes that appeared on old distractors than to probes that appeared either on new distractors $[t(7)=-3.05, p<.025]$ or at neutral locations $[t(7)=$
$-2.76, p<.05]$. There was no difference in detection for probes on new distractors or at neutral locations $(t<$ 1). At the $800-\mathrm{msec}$ interval, the opposite effects occurred. There was now worse detection of probes on old distractors than of probes that fell either on new distractors or at neutral locations $[t(7)=6.75$ and 3.45 , both $p \mathrm{~s}<.025]$. There was a nonsignificant trend for detection to be better on what would subsequently be new distractors than at neutral locations $[t(7)=-1.06, p>.10]$.

\section{Discussion}

The data for the 800-msec preview-probe interval replicated those found in Experiment 2: Probes were more difficult to detect when they fell at locations of old distractors than when they fell either at locations that would subsequently be occupied by new distractors or at

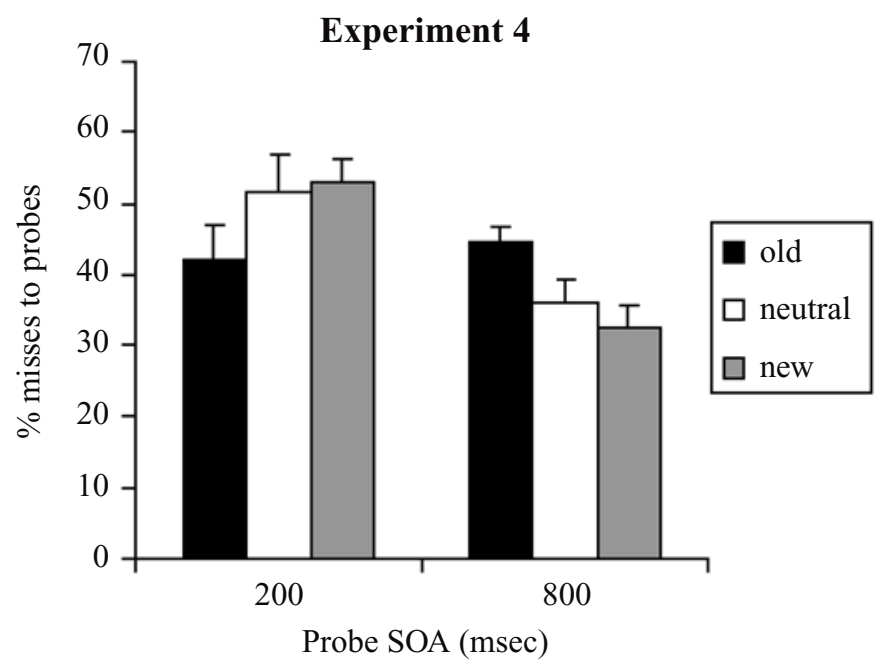

Figure 10. Percentages of misses to probes in Experiment 4 (preview search, stimulus onset asynchronies [SOAs] of 200 and $800 \mathrm{msec}$ ). Bars indicate the standard errors. 
neutral locations; detection at the latter locations did not differ. This result is consistent with old distractors being inhibited as the participants prioritized search for the new stimuli. In contrast to this, though, the detection of probes on old distractors was facilitated at the short previewprobe interval, relative to when probes fell at other locations (again, there was no effect of whether probes appeared at neutral locations or at locations that would subsequently be occupied by new distractors). This result suggests that the participants initially attended to the preview stimuli, prior to any occurrence of inhibition. We propose that initially, participants attend to the preview in order to encode stimuli into a representation in short-term memory. This memory representation is subsequently inhibited, in order to help prioritize the selection of new items. Note that this crossover result for detection of probes at old, relative to neutral, locations, at the two preview-probe intervals, makes it difficult to argue that poor detection of probes at old locations was due to some differential masking effect.

As in Experiments 2 and 3B, there was also some evidence for an effect of the probe on search RTs. RTs were longer on trials in which the probes appeared after $800 \mathrm{msec}$ than on trials in which the probes appeared after $200 \mathrm{msec}$. Presumably, some resources were devoted to probe detection, reducing the resources available for search when search followed shortly after the probes. There was also a tendency for this effect to occur only when probes were present (see Figure 9). As before, the location of the probe (at old, neutral, or new locations) did not affect search RTs substantially.

We also note that, in this study, we obtained a significant effect on probe detection of where the probe fell in the search display with as few as 8 participants. This makes it unlikely that our failure to find effects of probe location in Experiment 3 was due to a lack of power (there were 14 participants in both Experiment $3 \mathrm{~A}$ and Experiment 3B). Indeed, we have completed another replication, using just 13 participants, that confirmed the difference between probe detection at old and neutral locations after an 800-msec preview, when the probe procedure was embedded within the search task. ${ }^{1}$ The numbers of participants in Experiments 3A and 3B should have been sufficient to generate a reliable effect of probe location, if one was present.

\section{GENERAL DISCUSSION}

We have presented four experiments in which the time course of attention in preview search was examined, using a probe dot procedure. In Experiment 1, we demonstrated that the standard preview benefit (see Watson \& Humphreys, 1997) occurred with outline shapes and conditions in which the old and the new stimuli were not consistently defined by luminance increments (the colors defining the shapes, relative to the background grid, were close to isoluminance with one another, and the luminance of the grid elements changed randomly by $12 \%$ every $16 \mathrm{msec}$ ). In Experiment 2, we showed that there was impaired detection of probes falling on old distractors both when the probes appeared prior to the occurrence of the search displays (preview-probe interval of $800 \mathrm{msec}$ ) and when they appeared after the search displays (preview-probe interval of 1,200 msec). There was a tendency for probes to be better detected on new distractors than at neutral locations after the search displays had appeared. In addition to this, probe detection was more difficult at the long, relative to the short, previewprobe interval. Experiment 3 showed that these results were not due solely to the timing of the stimuli in the displays or to the effects of the color of the surrounding contour on probe detection. We found no differences in probe detection at old, neutral, and new locations when the participants were asked just to carry out the probe detection task (without search, Experiment 3A), and there was no effect of probe location in a conjunction search task in which the same colors were present but all the elements were presented together (Experiment 3B). There was also no evidence for color prioritization in the conjunction search task. In Experiment 4, preview-probe intervals of 200 and $800 \mathrm{msec}$ were used. At $800 \mathrm{msec}$, the data matched those in Experiments 2 and 3. At the short interval, however, there was facilitated detection of probes at old locations, relative to probes at neutral locations or at locations that would subsequently be occupied by new distractors.

These results provide evidence that inhibition of old items plays a role in preview search, since probes were more difficult to detect when they fell on old objects than when they appeared at neutral locations. This is very unlikely to have been due to a differential masking effect. First, probes were equidistant from the nearest contours in all three location conditions (with probes at the locations of new distractors, too). Second, the contours were close to or were actually isoluminant with one another, with individual contour elements also varying in brightness at random every $16 \mathrm{msec}$. Third, there was no effect of probe location in the control conditions of Experiment 3, when probe detection was prioritized and when conjunction search was undertaken. Fourth, there was a crossover interaction between probe location and preview-probe interval in Experiment 4, whereas masking should always have disrupted probe detection.

The finding that probes are hard to detect at old locations even before the search displays appear is inconsistent with several accounts of the preview effect, all of which presume that performance is contingent on the presentation of the search displays; these accounts include the new onset capture account (Donk \& Theeuwes, 2001), prioritized search of new items alone (Folk et al., 1992), and temporal grouping contingent on separate occurrence of preview and search displays (Jiang et al., 2002a, 2000b). It is also difficult to attribute the data solely to the role of some FINST-like process that indexes the locations of a small number of objects (Pylyshyn \& Storm, 1988). The data in Experiment 4 are consistent with participants' initially paying attention to the old items, but the FINST account provides no mechanism for 
the subsequent deprioritization of old items from search. The new onset capture account also has difficulty explaining the standard preview benefit in search (Experiment 1), given that search displays were not well defined by luminance increments here. Now, we do not wish to deny that such factors as a positive anticipatory set toward new stimuli and/or temporal grouping of old and new items may play a role in preview search. There may also be attentional capture by at least some of the new stimuli in search displays (although we stress that new object, rather than new onset capture, seems more viable when applied to the present data, where the objects were approximately isoluminant with the surrounding frame; see Yantis \& Hillstrom, 1994). However, our results indicate that these factors alone cannot provide a full account of the data. For example, if there is a positive anticipatory set toward new stimuli or temporal grouping of old and new displays, each process would need to be augmented by inhibition of old items in the context of the search task in order to explain the results. That is, performance is augmented by a process of visual marking (Watson \& Humphreys, 1997).

The present results do not provide any new information on the nature of the representations subject to visual marking, since probes appeared within old objects and at the same locations as those occupied by the old objects. Also, all of the old objects were in a particular color. Thus, marking could be object-, location-, or feature- (color) based here. Nevertheless, the prior evidence for poor probe detection at locations close to old items (Olivers \& Humphreys, 2002; Watson \& Humphreys, 2000), and also for negative carryover effects for stimuli with the same color as that of the old distractors in preview search (Olivers \& Humphreys, 2002, 2003), suggests that inhibition may be tied to both the location and the features of old stimuli (see also Olivers et al., 1999).

The behavioral results above are complemented by recent studies using functional brain imaging. Humphreys et al. (2004) examined preview search, using PET, and varied the preview interval across blocks of trials. They found that there was increased activation within the superior parietal lobe/precuneus as the preview interval lengthened. This did not reflect search behavior, since search times decreased at longer preview intervals (see Watson \& Humphreys, 1997). The increased activation is consistent with participants' constructing and/or inhibiting a representation of the old stimuli, which facilitates subsequent search. Prior work suggests that the superior parietal lobe is important for spatial coding of stimuli (e.g., Haxby et al., 1994). The increased activation in the superior parietal lobule, then, fits with participants' forming a location-based representation of old items (at least with static search displays). Pollmann et al. (2003) have extended these results further using fMRI. They found early and increased activation in the superior parietal lobe in preview search, relative to singlefeature and conjunction search conditions, and this occurred even on trials in which only the preview was pre- sented (with no search display), as compared with a display that was completely irrelevant to the subsequent search task. Thus, this superior parietal activation seems tied to the processing of the preview. In contrast, there was also early and increased activation in the right temporalparietal junction (TPJ) region that was linked to the ease of the search task (in the single-feature, as well as the preview, condition, as compared with the conjunction condition). The TPJ activity appears to be associated with the ease of discriminating the target, whereas the superior parietal activity seems linked to the encoding and segmentation of the old distractors.

The data from functional brain imaging suggest that, in preview search, an internal, location-based representation of old items is encoded in the superior parietal lobe. The notion of an initial encoding process also matches data from dual-task interference, where, irrespective of the modality of the secondary task, preview search is disrupted if the secondary task starts when previews appear (Humphreys et al., 2002). In the present study, we found that there was initially facilitated detection of probes on old distractors prior to the occurrence of any inhibitory effects (at the 200-msec preview-probe interval in Experiment 4). We attribute this to participants' initially attending to old items in order to encode them into memory. This memory representation is then subject to inhibition, in order to prioritize attention to new search displays.

If efficient preview search is based on an initial encoding of a memory representation of old items, we might also ask why there is little evidence for capacity limits contingent on the number of old items present (see, e.g., Theeuwes et al., 1998, for evidence of a preview benefit with up to 15 old items). Here, we suggest that capacity limits are reduced by encoding old items as a single group on the basis of their time, their common color (when they have a common color), and their configuration (see Kunar, Humphreys, Smith, \& Hulleman, 2003, for evidence of configural effects in preview search). Grouped old items can be inhibited together, and search can be biased away from them and toward a new set.

\section{Search and Probe Detection}

Like Olivers and Humphreys (2002) and Watson and Humphreys (2000), we found that probe detection was affected by the locations of the stimuli in the search display only when participants adopted a set to prioritize search (Experiment $3 \mathrm{~A}$ ). In addition to effects specific to the probe's location, the set for search for the new target also had a general detrimental influence on probe detection. There was about a $30 \%$ cost to probes appearing shortly after the onset of the new search display, as compared with when probes appeared beforehand (at the 800-msec SOA). When the search set was not adopted (Experiment $3 \mathrm{~A}$ ), this overall cost to probe detection was decreased. Similarly, the cost from appearing after the search display tended to reduce in the conjunction search task (when all the search stimuli appeared together; Experiment $3 \mathrm{~B}$ ). Thus, although some of this cost on probe 
detection may have occurred automatically, it was enhanced under preview search conditions. We suggest that when preview search was prioritized, attention would be engaged on the new search items as a single group when the probes appeared. This was less likely in conjunction search, where search was serial and unlikely to be engaged on a target by the time the probe appeared. In addition to this, we found that probes tended to disrupt search RTs to some degree, particularly when the probes appeared after the search display. This again suggests some overall competition for resources between the tasks. There was also a tendency for effects of probes on search to be greater on target-absent than on target-present trials, possibly because detection of the probe activated a present response, making the participants more cautious when responding absent. Importantly, though, it is difficult to see how competition from search could have generated the data on probe detection - particularly, the differences between old and neutral locations even at SOAs at which the probes preceded the search displays. We conclude that general tradeoffs between the tasks appeared over and above any inhibition of old distractors.

\section{Visual Marking and Other Inhibitory Processes in Search}

The present results provide positive evidence for a role of inhibitory processes applied against old items in preview search, over and above effects due solely to the temporal parameters of the displays (Experiment 3A) and over and above effects obtained in conjunction search (Experiment 3B). As we have discussed, other investigators have argued that a process of IOR is involved when participants conduct a serial search of a display, as is typically the case in conjunction search (Klein, 1988; Müller $\&$ von Mühlenen, 2000). For example, it has been proposed that IOR is applied to each previously inspected location, biasing search against returning there. We found little evidence for this in our probe detection study of conjunction search (Experiment 3B), although our probe detection procedure was not optimized to assess this (since probes appeared while search was taking place; see above). Nevertheless, there is a question of whether visual marking and IOR are independent or related processes. Olivers, Humphreys, Heinke, and Cooper (2002) attempted to examine this. They used a condition in which a target letter could appear among other, random letters, either in a preview or in a second search set. The target was presented in the second search set only after observers had searched the first set and then initiated the presentation of the second display. In each case, the target was likely selected following a serial search through the random letter distractors. Olivers et al. (2002) found that when the target appeared in the second search display, there was relatively little benefit from having the preview, relative to when all the search stimuli appeared together. Search was also much more efficient when the observers knew that the target was in the second set and so could, presumably, "mark" the preview. This result sug- gests that any IOR applied through search of the preview was not very effective in filtering old items from search, whereas marking was. Hence, there are grounds to distinguish visual marking from IOR applied during serial search. It may be, however, that IOR is not a unitary mechanism and that serial IOR applied to the locations of stimuli may be distinct from a more object-based process that biases search against previously attended stimuli (see Tipper, Driver, \& Weaver, 1991). Further work is needed to evaluate the relation between object-based IOR and visual marking of irrelevant old objects.

\section{REFERENCES}

Alais, D., BlaKe, R., \& LeE, S.-H. (1998). Visual features that vary together over time group together over space. Nature Neuroscience, $\underline{1}_{2}$ 160-164.

BLAKE, R., \& YANG, Y. (1997). Spatial and temporal coherence in perceptual binding. Proceedings of the National Academy of Sciences, 94, 7115-7119.

CEPEDA, N. J., CAVE, K. R., Bichot, N. P., \& Kim, M.-S. (1998). Spatial selection via feature-driven inhibition of distractor locations. Perception \& Psychophysics, 60, 727-746.

Chun, M. M., \& Wolfe, J. M. (1996). Just say no: How are visual searches terminated when there is no target present? Cognitive Psychology, 30, 39-78.

DonK, M., \& THEeUwes, J. (2001). Visual marking beside the mark: Prioritizing selection by abrupt onsets. Perception \& Psychophysics, 63, 891-900.

EGETH, H. E., \& YANTIS, S. (1997). Visual attention: Control, representation and time course. Annual Review of Psychology, 48, 269-297.

Folk, C. L., Remington, R. W., \& Johnston, J. C. (1992). Involuntary covert orienting is contingent on attentional control settings. Journal of Experimental Psychology: Human Perception \& Performance, $\underline{\mathbf{1 8}}$ 1030-1044.

GIBSON, B. S., \& JIANG, Y. (2001). Visual marking and the perception of salience in visual search. Perception \& Psychophysics, 63, 59-73.

Haxby, J. V., Horwitz, B., Ungerleider, L. G., MaisoG, J. M., Pietrini, P., \& GRAdY, C. L. (1994). The functional organization of human extrastriate cortex: A PET-rCBF study of selective attention to faces and locations. Journal of Neuroscience, 14, 6336-6353.

Humphreys, G. W., KyllingsBak, S., Watson, D. G., Olivers, C. N. L., LAW, I., \& PAulson, O. (2004). Parieto-occipital areas involved in efficient filtering in search: A time course analysis of visual marking using behavioural and functional imaging procedures. Quarterly Journal of Experimental Psychology, 57, 610-635.

Humphreys, G. W., Watson, D. G., \& Jolicceur, P. (2002). Fractionating visual marking: Dual task decomposition of the marking state by timing and modality. Journal of Experimental Psychology: Human Perception \& Performance, 28, 640-660.

JiANG, Y., Chun, M. M., \& MARKS, L. E. (2002a). Visual marking: Dissociating effects of new and old item set size. Journal of Experimental Psychology: Learning, Memory, \& Cognition, 26, 683-702.

JiAng, Y., Chun, M. M., \& Marks, L. E. (2002b). Visual marking: Selective attention to asynchronous temporal groups. Journal of Experimental Psychology; Human Perception \& Performance, 28, 717-730.

KLEIN, R. (1988, August 4). Inhibitory tagging system facilitates visual search. Nature, 334, 430-431.

Kunar, M. A., Humphreys, G. W., Smith, K. J., \& Hulleman, J. (2003). What is "marked" in visual marking? Evidence for effects of configuration in preview search. Perception \& Psychophysics, $\mathbf{6 5}$, 982-996.

LEE, S.-H., \& BlaKe, R. (1999). Visual form created solely from temporal structure. Science, 284, 1165-1168.

LeOnARDS, U., SingER, W., \& FAHLE, M. (1996). The influence of temporal phase differences in texture segmentation. Vision Research, $\underline{\mathbf{3 6}}$, 2689-2697.

MÜLleR, H. M., \& VON MÜHLENEN, A. (2000). Probing distractor in- 
hibition in visual search: Inhibition of return. Journal of Experimental Psychology: Human Perception \& Performance, 26, 1591-1602.

OLIVERS, C. N. L., \& HuMPhreys, G. W. (2002). When visual marking meets the attentional blink: More evidence for top-down limited capacity inhibition. Journal of Experimental Psychology: Human Perception \& Performance, 28, 22-42.

OLIVERS, C. N. L., \& HuMPHREYS, G. W. (2003). Visual marking and singleton capture: Fractionating the unitary nature of visual selection. Cognitive Psychology, 47, 1-42.

Olivers, C. N. L., Humphreys, G. W., Heinke, D., \& Cooper, A. C. G. (2002). Prioritization in visual search: Visual marking is not dependent on a mnemonic search. Perception \& Psychophysics, 64, 540-560.

Olivers, C. N. L., Watson, D. G., \& Humphreys, G. W. (1999). Visual marking of locations and feature maps: Evidence from withindimension defined conjunctions. Quarterly Journal of Experimental Psychology, 52A, 679-715.

Pollmann, S., Weidner, R., Humphreys, G. W., Olivers, C. N. L., Müller, K., Lohmann, G., Wiggins, C. J., \& Watson, D. G. (2003). Separating distractor rejection and target detection in posterior parietal cortex: An event-related fMRI study of visual marking. NeuroImage, 18, 310-323.

PyLYSHYN, Z. W., \& STORM, R. W. (1988). Tracking multiple independent targets: Evidence for a parallel tracking mechanism. Spatial Vision, 3, 179-197.

Theeuwes, J., Kramer, A. F., \& Atchley, P. (1998). Visual marking of old objects. Psychonomic Bulletin \& Review, 5, 130-134.

TipPer, S. P., Driver, J., \& WeAVER, B. (1991). Object-centered inhibition of return of visual attention. Quarterly Journal of Experimental Psychology, 43A, 289-298.
Watson, D. G., \& Humphreys, G. W. (1997). Visual marking: Prioritizing selection for new objects by top-down attentional inhibition of old objects. Psychological Review, 104, 90-122.

Watson, D. G., \& Humphreys, G. W. (2000). Visual marking: Evidence for inhibition using a probe-dot detection paradigm. Perception \& Psychophysics, 62, 471-481.

WOLFE, J. M., \& POKORNY, C. W. (1990). Inhibitory tagging in visual search: A failure to replicate. Perception \& Psychophysics, 4 48, 357362.

Yantis, S., \& Hillstrom, A. P. (1994). Stimulus-driven attentional capture: Evidence from equiluminant visual objects. Journal of Experimental Psychology: Human Perception \& Performance, 20, 95107.

YAnTIS, S., \& Jones, E. (1991). Mechanisms of attentional selection: Temporally modulated priority tags. Perception \& Psychophysics, $\mathbf{5 0}_{2}$ 166-178.

YANTIS, S., \& JoNidES, J. (1984). Abrupt visual onsets and selective attention: Evidence from visual search. Journal of Experimental Psychology: Human Perception \& Performance, 10, 601-621.

\section{NOTE}

1. The mean percentages of correct probe misses were $41.1 \%, 32.5 \%$, and $32.7 \%$ for probes falling at old, new, and neutral locations, respectively. There was an overall difference between the conditions $[F(2,26)=$ $5.00, p<.025]$, with more misses made to probes at old locations than to probes at either new locations or neutral locations $[F(1,13)=9.75$ and $6.59, p<.01$ and .025 , respectively]. Detection did not differ for probes at old and new locations $(F<1)$. 